\title{
Summer Sea Surface Temperature Variability off Vancouver Island From Satellite Data
}

\author{
WENDONG FANG ${ }^{1}$ AND WILLIAM W. HSIEH \\ Department of Oceanography, University of British Columbia, Vancouver, Canada
}

\begin{abstract}
Satellite-sensed advanced very high resolution radiometer (AVHRR) sea surface temperature (SST) data over eight summers (1984-1991) were used to analyze the summer SST patterns of variability off the west coast of Vancouver Island. Empirical orthogonal function (EOF) analysis of the spatial variance for 133 nearly cloud-free summer images was performed. The first EOF mode, which resembled the mean of all images, showed a strong cool water band located at the northwest corner of Vancouver Island, a cool tongue extending seaward from the Strait of Juan de Fuca and a warm patch off Barkley Sound. The second mode revealed topographically controlled upwelling: cool water over the shelf region with its seaward boundary roughly following the $200-\mathrm{m}$ depth contour, plus a cold eddy located just north of the Juan de Fuca Canyon. The third mode displayed cool water extending southwestward off Brooks Peninsula, while the fourth mode showed a cool water plume extending off Cape Scott at the northern tip of Vancouver Island. These four modes accounted for $33,12,10$, and $5 \%$ of the SST variance, respectively. The temporal amplitude of these EOF modes revealed how the SST features changed as summer progressed. From these images, we also constructed an overall seasonal coolness index, which revealed the summers of 1986 and 1991 to have the coolest coastal water, with both summers immediately preceding an El Niño.
\end{abstract}

\section{INTRODUCTION}

With the increasing availability of satellite sea surface temperature (SST) data, it has become possible to use satellite data to monitor SST variability in both space and time, improving vastly on the very limited spatial coverage offered by ship observations. Off the west coast of Vancouver Island, SST images of the summer coastal upwelling were used to study baroclinic instability [Emery and Mysak, 1980], eddies, upwelling events and coastal currents [Ikeda and Emery, 1984; Thomson and Gower, 1985; Burgert and Hsieh, 1989] and to compare with numerical modeling results [Ikeda et al., 1984]. Thomson et al. [1989] gave a general description of the circulations off Vancouver Island, showing the spatial and temporal variability of the coastal current and its effects on the coastal fishery. Former studies related to the SST variability off Vancouver Island used satellite data mainly for descriptive purposes by examining individual images over a short period. In this study, the nearly cloud-free SST data extending over eight summers were used to study the longer term SST variability.

Empirical orthogonal function (EOF) analysis (also known as principal component analysis) is generally regarded as the most efficient way to extract information from large data sets. For the past few years, EOF analysis has been used to extract dominant satellite SST patterns

\footnotetext{
${ }^{1}$ Also at South China Sea Institute of Oceanology, Academia Sinica, Guangzhou, China.

Copyright 1993 by the American Geophysical Union.

[Kelly, 1985; Lagerloef and Bernstein, 1988; Paden et al., 1991]. There are several ways to calculate the EOFs, but no matter which method is used, the solution is unique for the nonmissing data $[K e l l y, 1988]$. While the analysis methods are the same whether a temporally averaged mean or a spatially averaged mean is first removed from the data set, different EOFs are obtained [Paden et al., 1991]. Lagerloef and Bernstein [1988] suggested that for satellite images where spatial features tended to be persistent or only weakly time varying, spatial EOFs (i.e., EOFs performed on data with their spatial means removed) were more appropriate than temporal EOFs, which mainly explained structures with strong temporal variability. This property was also found by Paden et al. [1991] while using EOFs to analyze the patterns of SST variability in the Gulf of California in relation to tidal and wind forcing.

In this paper, the purpose is to identify the dominant patterns of summer SST variability off Vancouver Island using EOFs, and to study the seasonal and interannual variability in the coastal upwelling. This paper is organized as follows: Section 2 introduces the collection and processing of advanced very high resolution radiometer (AVHRR) SST data. After briefly describing the EOF method in section 3, we show the dominant EOF modes and relate them to oceanographic structures in section 4. Section 5 presents the coolness index derived from the SST images, while section 6 performs correlation analysis between the time series of EOF temporal amplitudes and various indices which affect the SST in the study region.

\section{Data Collection and Processing}

In this study, the primary data source was satellite imagery from polar-orbiting NOAA satellites. The Universi- 
ty of British Columbia (UBC) Satellite Oceanography and Meteorology Laboratory has received and processed 133 nearly cloud-free AVHRR images off Vancouver Island during eight summers (1984-1991) via these NOAA satellite series. All satellite images were navigated (i.e. corrected for distortion and registered to a map), and were nudged (i.e., entire image shifted to fit map overlap) to correct for receiving system timing errors or satellite altitude errors. The accuracy of the navigation was about 1 pixel $(1.1 \mathrm{~km})$. The navigation and cloud detection techniques used in this study were described in Emery et al. [1986]. Only infrared images from band $4(10.3-11.3 \mu \mathrm{m})$ were converted to brightness SST [Lauritson et al., 1979]. Since SST variability rather than absolute SST is important in this study, no correction was made for the atmospheric water vapor effect on the infrared temperature.

The irregular temporal coverage of the images might cause serious aliasing as some short-term events might be missing in the satellite data. However, there is little doubt that the main variability features can be covered by the satellite data, as discussed in Kelly [1985]. In our study, we focus on the larger scale and longer term SST variability, so the effects from the irregularity of time series may not be too serious. A limited test on the seriousness of missing temporal coverage will be shown in section 5 .

The study area (Figure 1) is about $350 \mathrm{~km}$ alongshore by $150 \mathrm{~km}$ offshore, covering the entire continental shelf and slope region off Vancouver Island. For the convenience of computation and analysis, we resampled the spatial grids (Figure 2), so that the SST spatial resolution changed from the original $1.1 \mathrm{~km}$ by $1.1 \mathrm{~km}$ pixel to $1.5 \mathrm{~km}$ by $1.5 \mathrm{~km}$. A spatial weighted moving filter matrix

$$
F=\frac{1}{16}\left[\begin{array}{lll}
1 & 2 & 1 \\
2 & 4 & 2 \\
1 & 2 & 1
\end{array}\right]
$$

was used to smooth the SST data and to reduce small scale image noise [Wang et al., 1983]. Each selected image was at least $85 \%$ cloud-free over the study region. There were 105 by 253 spatial data points over the study area. The data were arranged into a two-dimensional array $T(x, t)$, where $x$ and $t$ were the spatial and temporal indices, respectively.

\section{The EOF MethoD}

The application of EOF analysis to satellite infrared data has previously been presented by Kelly [1985], Lagerloef and Bernstein [1988] and Paden et al. [1991]. EOFs are the principal axes of a data covariance matrix, with the EOFs usually ordered decreasingly by eigenvalue. The first few EOFs denote the dominant patterns of the variance with the corresponding eigenvalues representing the percentages of total variance accounted for.

In order to explicitly decompose just the spatial or just the temporal variability of SST, one of two different means must be removed from $T(x, l)$ before calculating the data covariance matrix. To study the strongly temporal patterns associated with warming or cooling of some study area, temporally averaged mean at each point is removed from the data, i.e.,

$$
T^{\prime}(x, t)=T(x, t)-\frac{1}{N} \sum_{t=1}^{N} T(x, t)
$$

where $t$ represents a particular image in the data set and $N$ the total number of images.

In contrast, for the study area where structures vary very strongly in space but weakly in time (e.g., fronts, upwelling or topographic eddies), spatially averaged mean in each image is removed from the data, i.e.,

$$
T^{\prime}(x, t)=T(x, t)-\frac{1}{M} \sum_{x=1}^{M} T(x, t)
$$

where $M$ is the total number of pixels in an image.

Lagerloef and Bernstein [1988] called the resulting EOFs from removing temporal means, "temporal EOFs", and those from subtracting spatial means, "spatial EOFs". For convenience of discussion and to avoid confusing terminology, Paden et al. [1991] called the former "covariance EOFs", and the latter "gradient EOFs". Lagerloef and Bernstein [1988] and Paden et al. [1991] used both approaches to analyze the SST patterns of variability. They suggested that the approach with spatial means removed was more suitable for AVHRR SST patterns where oceanographic features tended to persist over time. This hypothesis was tested with our satellite SST data and similar results were obtained. Hence, we will concentrate mainly on the gradient EOFs in the following section.

The EOF decomposition of the data set $T^{\prime}(x, t)$ to form the covariance matrix is a linear combination of eigenfunctions,

$$
T^{\prime}(x, t)=\sum_{n=1}^{N} a_{n}(t) F_{n}(x)
$$

with the coefficient $a_{n}(t)$ obtained by projecting the data set onto each function $F_{n}(x)$,

$$
a_{n}(t)=\sum_{x=1}^{M} T^{\prime}(x, t) F_{n}(x)
$$

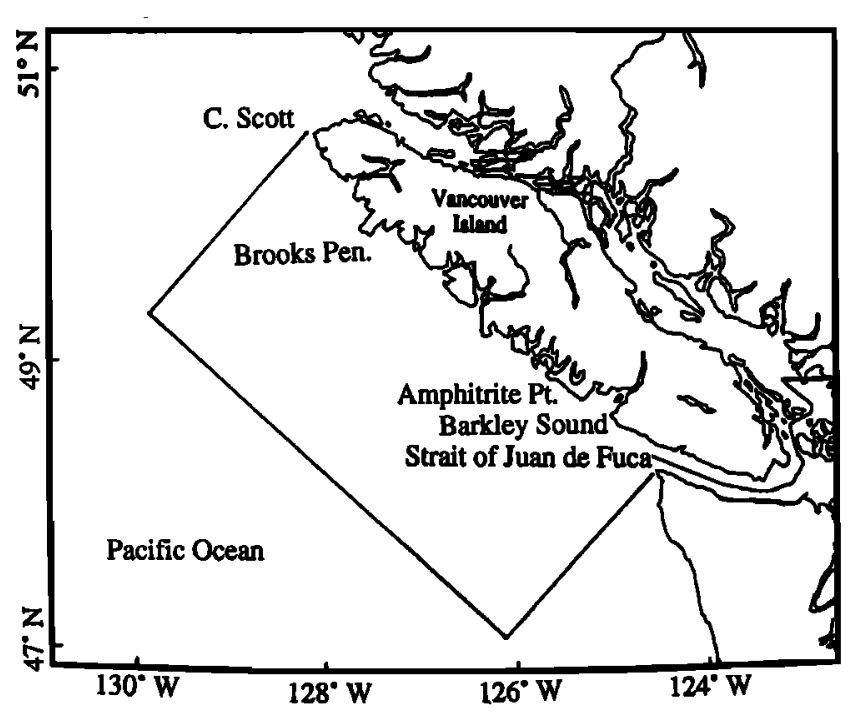

Fig. 1. Study area off the west coast of Vancouver Island. 


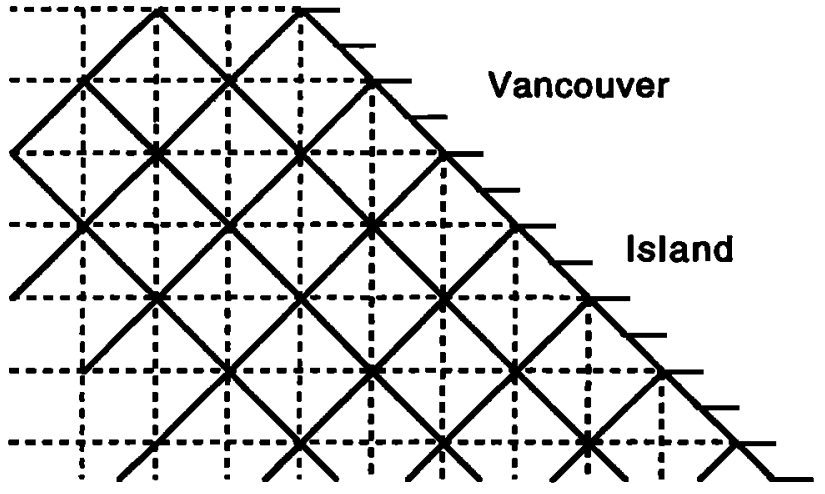

Fig. 2. The solid grid indicates the center of re-sampled pixels, whereas the dashed grid shows the center of the original pixels.

With this presentation, $F_{n}(x)$ is called the spatial amplitude, which presents the spatial covariance pattern of an EOF mode, while the coefficient $a_{n}(t)$ is called the temporal amplitude, which describes the time variations of an EOF mode.

The EOFs are calculated by solving the eigenvalue problem of the data covariance matrix (formed by multiplying the data matrix $T^{\prime}$ by its transpose). Instead of solving for the eigenvectors of the covariance matrix (the "covariance method"), one can also calculate singular vectors by using singular-value decomposition (SVD). Hence, there are at least two different ways to calculate EOFs, but the solution is unique when there are no data missing [Kelly, 1988]. With SVD, missing data must be estimated [Kelly, 1985; Paden et al., 1991], but fewer computations are required. In contrast, the use of the covariance method allows one to simply skip over missing data. The latter method is used in this study. For the details of the covariance method and the processing technique for calculating the data covariance matrix from the data set $T^{\prime}(x, t)$ where rows outnumber columns, see Lagerloef and Bernstein [1988].

\section{EOF ANALYSIS OF THE SST PATtERnS OFF VANCOUVER ISLAND}

The spatial patterns of the first four gradient EOF modes are presented in Figure 3, and their corresponding temporal amplitudes in Figure 4. The first gradient EOF (Figure 3a), accounting for $33 \%$ of the total variance, shows positive spatial amplitudes in the southwest corner of the study area and in a small region off Barkley Sound. The negative spatial amplitudes cover the northeast area offshore from the northwest coast of Vancouver Island and the region offshore from the Strait of Juan de Fuca. As the temporal amplitude of this mode was almost always positive (Figure $4 a$ ), the negative spatial amplitudes represent the cooler water. For the area more than $75 \mathrm{~km}$ offshore, the spatial amplitudes decrease from south to north, revealing a northward cooling trend. The spatial pattern of the first mode is very similar to the mean temperature field from averaging over all 133 images (not shown). But mode 1 provides more information than the mean pattern by revealing the temporal behavior (Figure $4 a$ ) of this pattern.

In Figure $3 a$, the cool water band along the northwest coast of Vancouver Island appears to originate from the northern tip of Vancouver Island and then flow southward past Brooks Peninsula. This cool water band can often be observed from individual images during summer and its somewhat uncertain source (from northem tip of Vancouver Island or from Brooks Peninsula) has been argued by Ikeda and Emery [1984] and Emery et al. [1986]. Another cool water core originates from the mouth of Juan de Fuca Strait. The flow of this cool water must be affected strongly by the discharge from the strait, and by upwelling induced by the complex local topography, e.g., the Juan de Fuca canyon [Freeland and Denman, 1982]. From numerical simulations [Weaver and Hsieh, 1987], the discharge should flow northward along the coast. However, with shallow banks to its north forming a northern "barrier", the cool surface water appears to deflect seawards during its northward flow [Thomson et al., 1989]. The persistence of this feature implies that despite upwelling favorable wind, which opposes the flow, this cool water still flows northward because of peak discharge from the strait during summer. The small patch of warm surface water off Barkley Sound separates the Juan de Fuca cold tongue and the cool water off the northwest coast of Vancouver Island. This warm feature has also been observed from the summertime individual images by Emery et al. [1986], who suggested that this warm water over the shallow banks off Barkley Sound was related to solar heating in this region, especially in Barkley Sound. Thomson et al. [1989] systematically described the circulation mechanism over the shallow topographically complex banks, pointing out that the summer circulation over the region was weak, and tidal rectification and outflow of the water in Barkley Sound played an important role in the region. The velocity EOF analysis in this region by Hickey et al. [1991], showed the first EOF of velocity at $30 \mathrm{~m}$ depth off Barkley Sound to be directed weakly offshore, confirming the seaward-flowing feature of this warm water band.

Gradient EOF mode 2, accounting for $12 \%$ of the total variance, shows a zero-crossing along the continental slope (Figure $3 b$ ). Except for being further offshore, the zero crossing is closely aligned with the 200-m depth contour which is about $65 \mathrm{~km}$ offshore in the southern portion and less than $5 \mathrm{~km}$ offshore off Brooks Peninsula. This $200 \mathrm{~m}$ depth contour indicates the shelf-break region where upwelling is a common feature in summer [Freeland and Denman. 1982; Ikeda and Emery, 1984; Denman and Freeland, 1985]. The seaward extension of the cool water beyond the shelf break may be caused by the offshore Ekman transport in wind-induced upwelling. Ikeda and Emery [1984] noticed that the cool water boundary propagated offshore at $10 \mathrm{~km} / \mathrm{d}$, extending eventually beyond the shelf break. The largest negative spatial amplitude occurred just north of the Juan de Fuca canyon, where a topographically controlled cyclonic eddy is often found [Freeland and Denman, 1982; Denman and Freeland, 1985; Weaver and Hsieh, 1987]. When the temporal amplitude of this mode (Figure $4 b$ ) is positive, this pattern describes the topographically controlled, wind-induced upwelling over the entire shelf-slope region with the coolest surface water located in the southeast region. Freeland and Denman [1982] also found summertime upwelling to be especially pronounced at the edges of the southern banks owing to the presence of major canyons. During upwelling, 
(A) SPATIAL AMPLITUDE FOR EOF MODE ONE

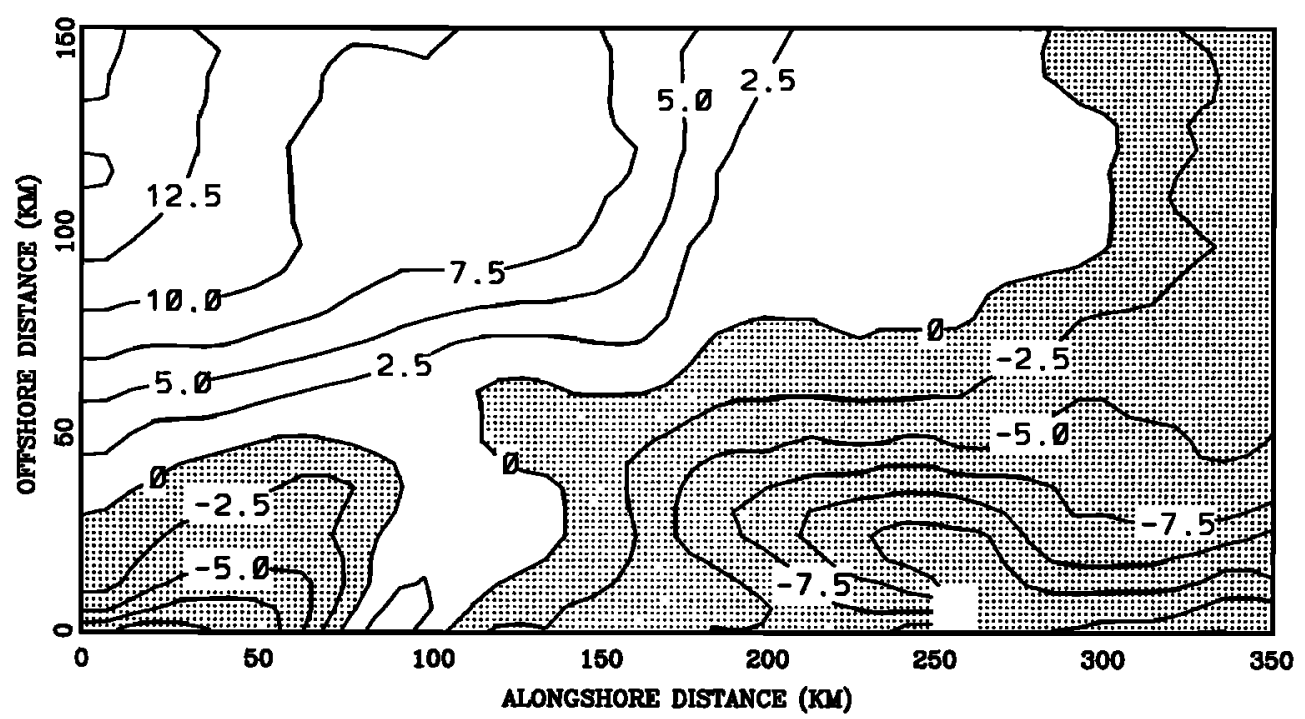

(B) SPATIAL AMPLITUDE FOR EOF MODE TWO

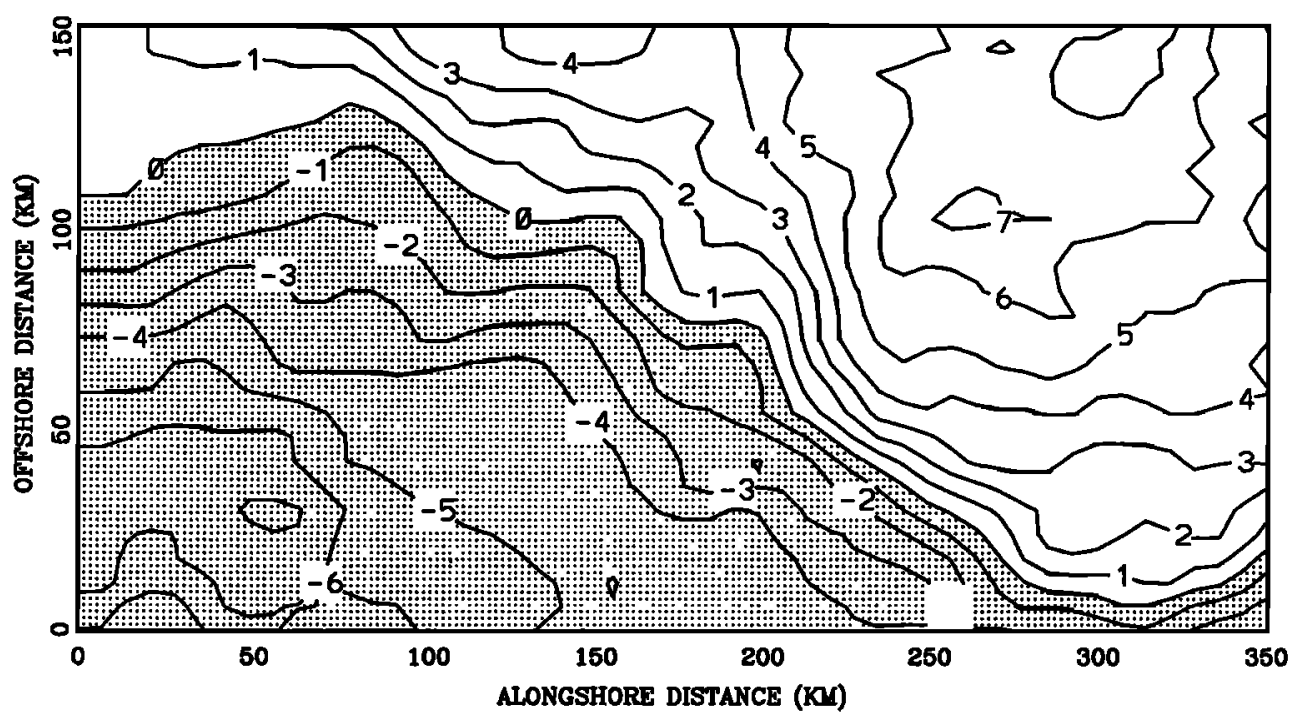

Fig. 3. Spatial amplitude patterns for the SST gradient EOF modes 1 to 4 . The spatial domain extends $150 \mathrm{~km}$ offshore and $350 \mathrm{~km}$ alongshore. In the alongshore direction, the mouth of the Juan de Fuca Strait stretches from 0 to $30 \mathrm{~km}$, Barkley sound from 70 to $90 \mathrm{~km}$, and Brooks peninsula protrudes from the coast at $250 \mathrm{~km}$ alongshore.

the temporal variability of this mode may also be related to the remotely wind-driven coastally trapped waves. This type of upwelling structure may be present during summer despite weak or downwelling-favorable local winds [Thomson et al., 1989].

Explaining $10 \%$ of the total variance, the third gradient EOF mode shows a large tongue of negative amplitude extending southwestward from Brooks peninsula. A similar cold water band has been observed in 1980 summertime images [Iked $a$ and Emery, 1984]. They argued that this band appeared to be advected by the southward flow from the cooler northern district, but could also be the expression of upwelling at the local shelf break. When the temporal amplitude is positive, this mode represents the presence of a "squirt" or seaward jet of cool water. In the southern region, the amplitude values are positive, implying an out-of-phase relation with the squirt region.

The fourth mode explains $5 \%$ of the total variance. When the temporal amplitude is positive, this mode represents a cold plume originating off Cape Scott at the northern tip of Vancouver Island and extending seaward. For these higher modes, we need to determine if they are statistically significant. A significance test introduced by $O$ verland and Preisendorfer [1982] uses the Monte Carlo technique for selecting EOFs. However, when the data set is very large, the cost of Monte Carlo simulations becomes excessive. 
(C) SPATIAL AMPLITUDE FOR EOF MODE THREE

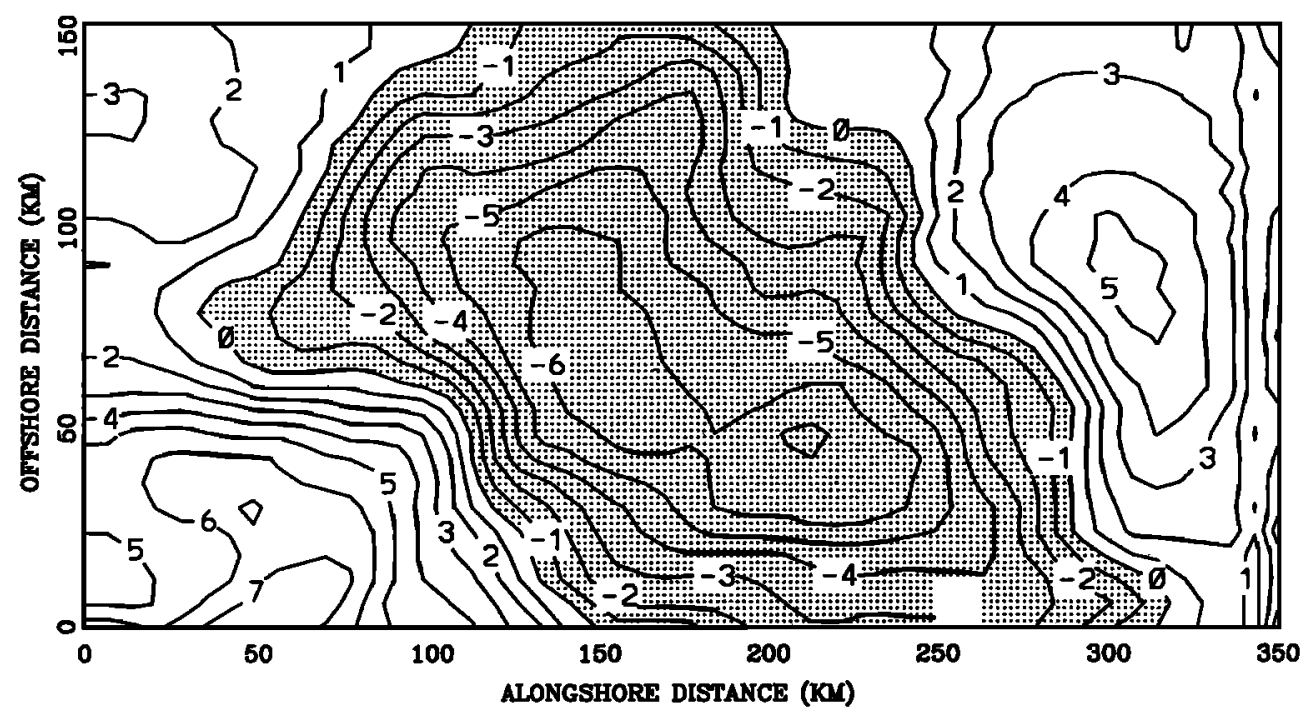

(D) SPATIAL AMPLITUDE FOR EOF MODE FOUR

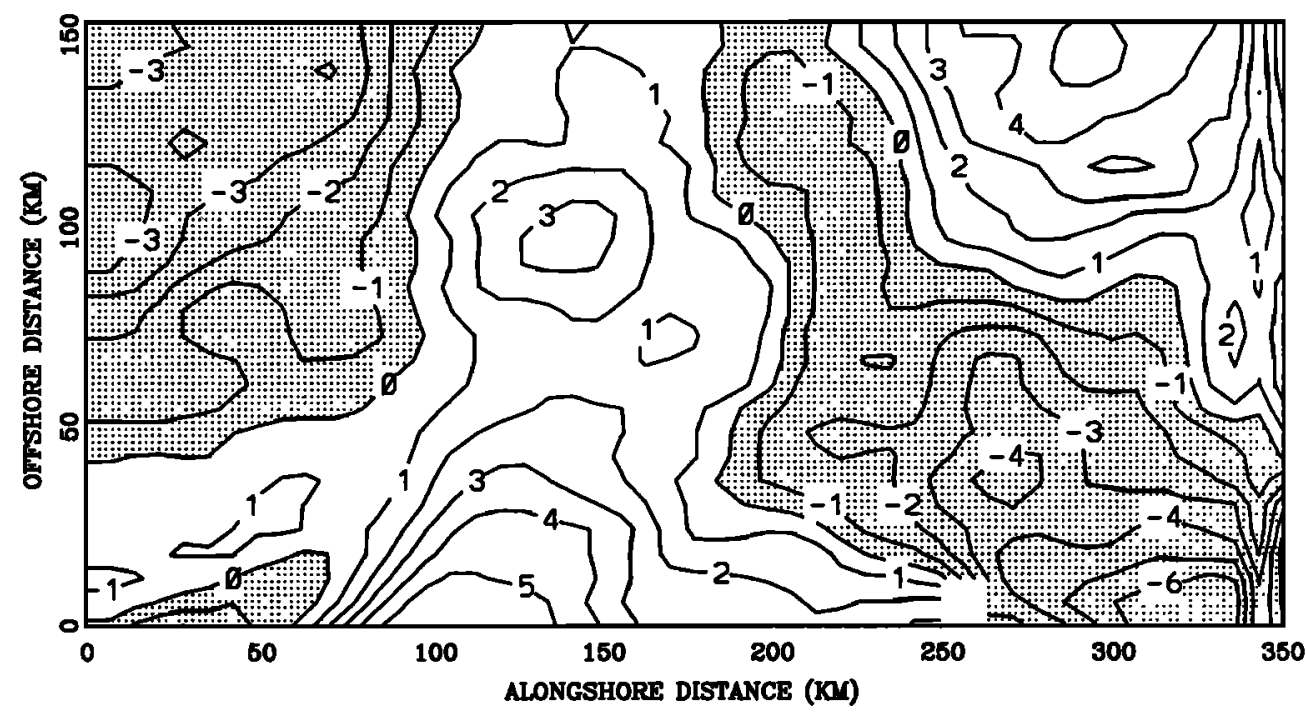

Fig. 3. (continued)

Instead, the asymptotic theory for large data sets can be used [Preisendorfer, 1988, p. 204-205]. As the data set in this study is large, we used the the asymptotic method to test the significance of the EOFs. From Preisendorfer [1988, equation 5.18] (but with the incorrect minus sign preceding $(a b)^{1 / 2}$ replaced by a plus sign), we found that the first 13 EOF modes were above the $99 \%$ significance level.

In summary, the first four gradient EOF modes, altogether accounting for $60 \%$ of the SST variance, represented some of the well-known features in the region. The first mode closely resembled the mean summer upwelling pattern, the second, the topographically controlled upwelling, the third, the squirt off Brooks Peninsula, and the fourth, the northern plume off Cape Scott. Figure 5 shows the temporal amplitude averaged over the particular summer months during 1984-1991. The temporal amplitude for mode 1 increases monotonically from June to September, revealing the intensification of the mode 1 pattern (Figure $3 a$ ) as the summer progresses. Mode 2 also intensifies from June, peaking in August. Mode 3 shows a decline in the temporal amplitude in August and especially in September, implying a decrease in the likelihood of a strong squirt off Brooks Peninsula as summer progresses.

The temporal amplitudes for the EOFs were also averaged over each summer (Table 1), revealing that the mode 1 type of SST pattern was strongest in 1990. The mode 2 type of upwelling was strongest in 1991 and 1986.

In order to compare with the gradient EOFs, covariance EOFs (i.e., with the temporal mean removed from the data as in (2)) were also calculated. The first three covariance EOF modes (not shown) accounted for 55.8, 6.9, and 6.6\% of the total variance, respectively. The covariance EOF 
(a) Mode 1

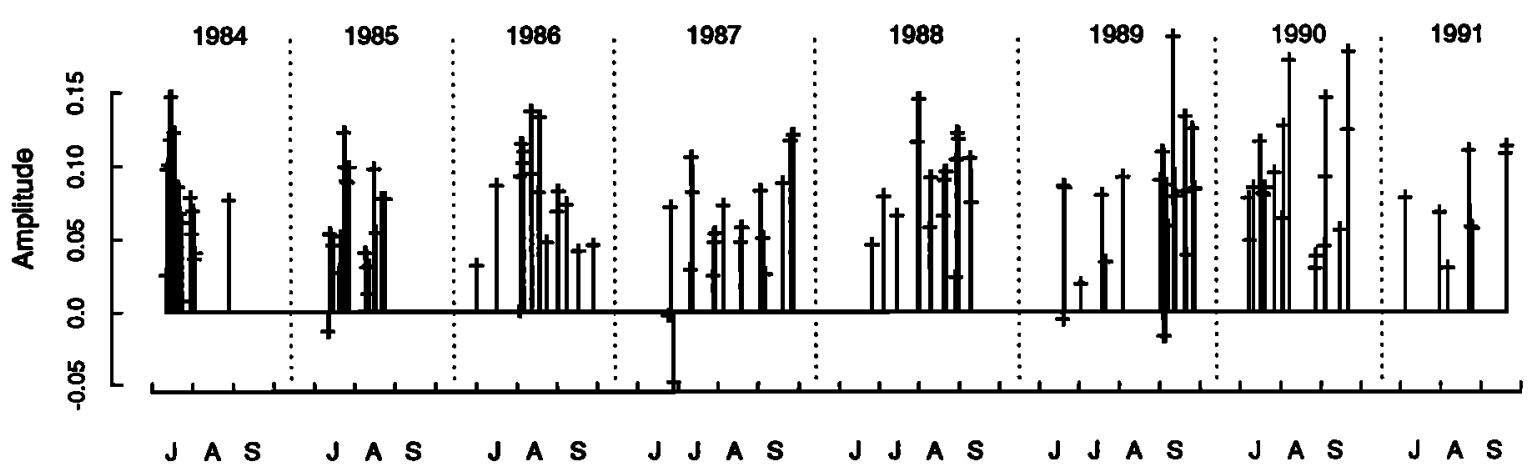

(b) Mode 2

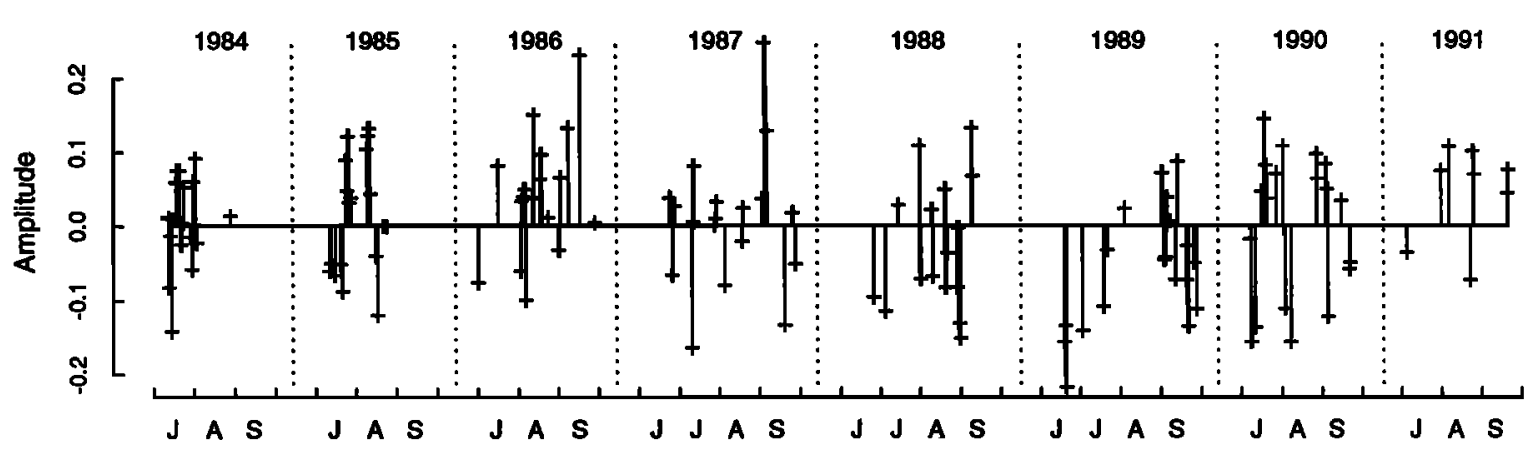

(c) Mode 3

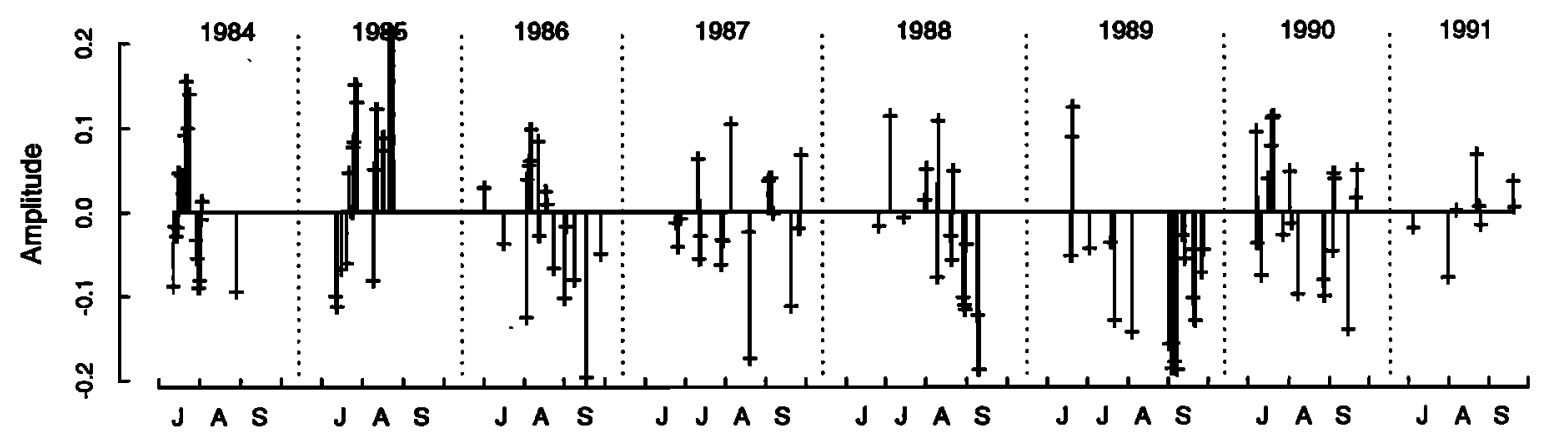

(d) Mode 4

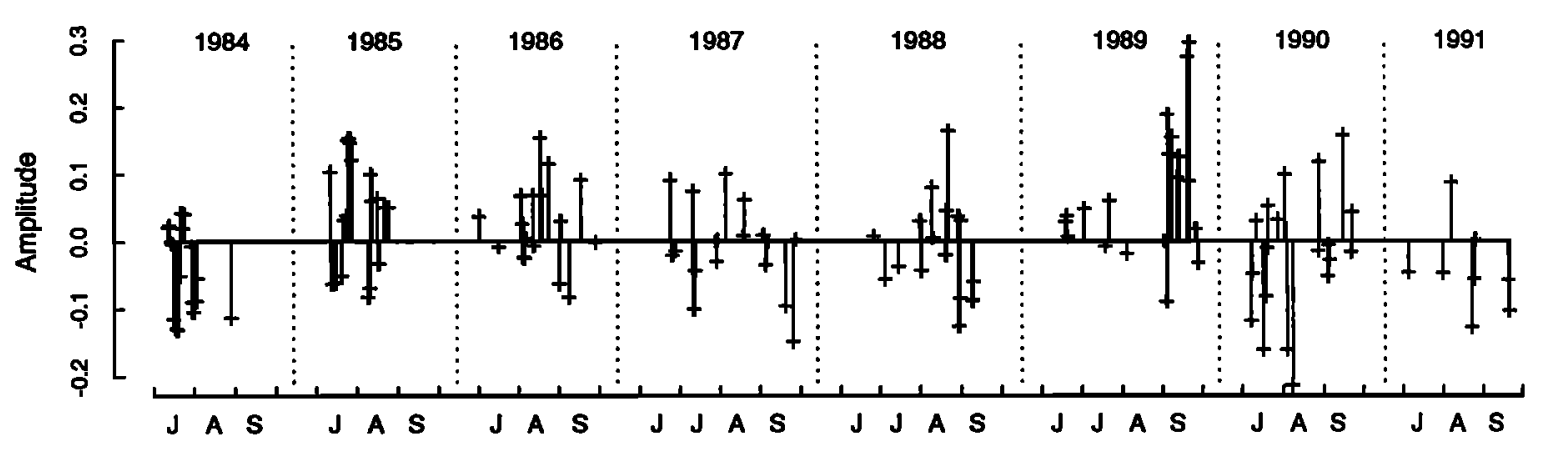

Fig. 4. Temporal amplitude for the SST gradient EOF modes 1 to 4. 
AVERAGED TEMPORAL AMPLITUDE OF EOF MODES

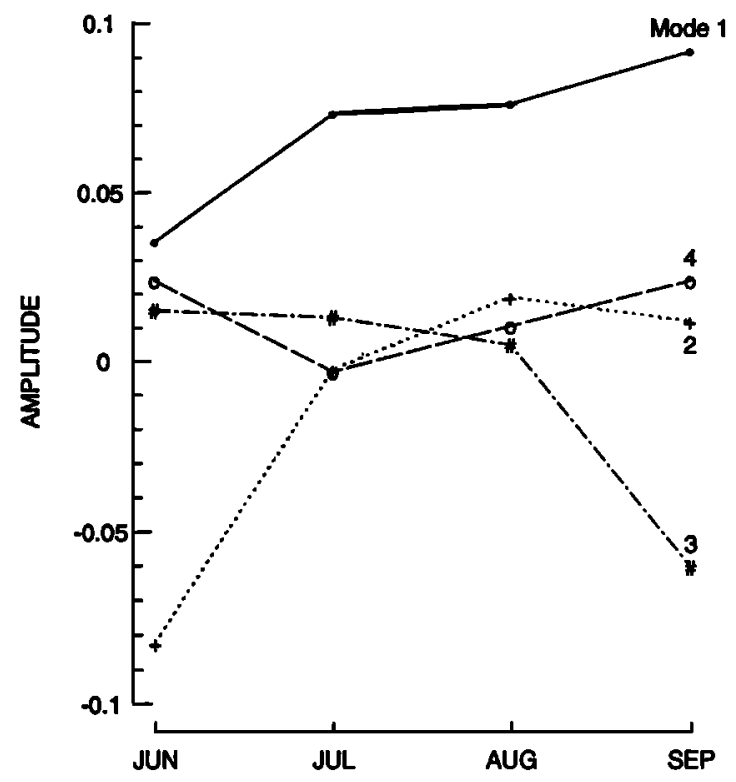

Fig. 5. The monthly averaged temporal amplitudes of the gradient EOF modes 1 to 4 over all years, revealing the monthly progression of the SST patterns as summer advances.

spatial patterns for modes 1, 2, and 3 resembled gradient EOF modes 1, 3 and 2, respectively, though the covariance EOF patterns were much noisier than the corresponding gradient EOF patterns.

\section{A COOLNESS INDEX}

It would be useful to define a simple index that characterizes the relative strength of the coastal cool water. By calculating the difference between adjacent pixel values, we located the maximum temperature gradient in the offshore direction, thereby defining an offshore SST front a distance $d$ from the coast (Figure 6). We then chose a line, $7.5 \mathrm{~km}$ seaward from the SST front, as a boundary to divide the study area into two: the shoreward part representing the cool, upwelling region, and the seaward part, the warmer open ocean. The overall coolness index $C$, which represents a regional average of the relative mass of cold water, is defined as

$$
C=\frac{\sum_{J=J=f(J)}^{253} \sum_{J=f\left(\bar{T}_{\text {ocean }}(J)-T(I, J)\right) S(I, J)}^{105}}{\sum_{J=1 /=f(J)}^{253} \sum_{I=J}^{105} S(I, J)}
$$

where $I, J$ denote the onshore and alongshore indices of each pixel, $S(I, J)$ the pixel area and $T\left(I_{r} J\right)$ the temperature at that pixel. $\bar{T}_{\text {ocean }}(J)$ denotes the temperature averaged along row $J$ over the region seaward of the partitioning line $I=f(J)$ (shown as the dashed contour in Figure 6). The summations in (6) are over the shoreward region from the partitioning line $I=f(J)$.

The mean coolness index $C$ for each summer, estimated by averaging the individual $C$ values from each image over
TABLE 1. Summer SST Indices off Vancouver Island from 1984 to 1991

\begin{tabular}{ccccccc}
\hline Summer & $a_{1}$ & $a_{2}$ & $a_{3}$ & $a_{4}$ & $d$ & $C$ \\
\hline 1984 & 7.5 & 1.0 & 1.0 & -4.1 & 70 & 0.59 \\
1985 & 6.3 & 1.9 & 5.2 & 4.5 & 73 & 0.64 \\
1986 & 8.1 & 4.7 & -1.4 & 3.1 & 71 & 0.92 \\
1987 & 5.9 & 1.2 & -1.3 & -0.3 & 65 & 0.54 \\
1988 & 9.0 & -2.2 & -3.0 & -0.3 & 65 & 0.51 \\
1989 & 7.8 & -5.5 & -7.7 & 7.8 & 72 & 0.42 \\
1990 & 9.4 & 0.5 & 0.4 & -1.6 & 65 & 0.81 \\
1991 & 8.0 & 4.9 & 0.4 & -4.0 & 80 & 0.86 \\
\hline
\end{tabular}

Monthly averages of the indices were first calculated from the images for the months June to September, then averaged to form the summer index. The $a_{n}$ are the summer values of the temporal amplitudes (in \%) of the gradient EOF modes 1 to 4. The $d$ are the offshore locations of the front in kilometers, and $C$ are the coolness indices in degrees Celsius.

each summer, indicated that coolest coastal water occurred in 1986 and 1991 (Figure 7). As the $C$ index measures the average temperature anomaly in the coastal upwelling region with respect to the temperature in the offshore region, these strong anomalies in the $C$ index indicated that the shelf water was relatively cool in the summers of 1986 and 1991. The mean offshore location of the front (Table 1) was also greatest in 1991 ( $80 \mathrm{~km}$ offshore). The years 1987, 1988 and 1990 had the front closest to the shore (at $65 \mathrm{~km}$ offshore).

As the satellite data are available only during cloud-free periods, we have to question the reliability of our summer upwelling index. To test the interference of clouds, we deliberately computed $C$ with data missing at a 2-week period during different times in each summer. Figure 8 shows that the fluctuations of these $C$ values computed with missing data were in general smaller than the interannual variability in $C$, therefore giving us confidence that the interannual variability in $C$ observed was above the noise generated by missing data from cloudy periods. Figure 8 also shows that missing data in June (when upwelling was still immature) tended to result in $C$ being shifted higher, whereas missing data in September (when upwelling was mature) tended to result in $C$ being shifted lower.

The coolness index $C$ covers two E1 Niño events (19861987 and 1991-1992). As the strongest $C$ occured in the summers of 1986 and 1991 , this suggests that the $C$ index leads the El Niño events. This result was tested by calculating the lagged correlation between the $C$ index and the seasonal Southern Oscillation Indices (SOI) (i.e., the

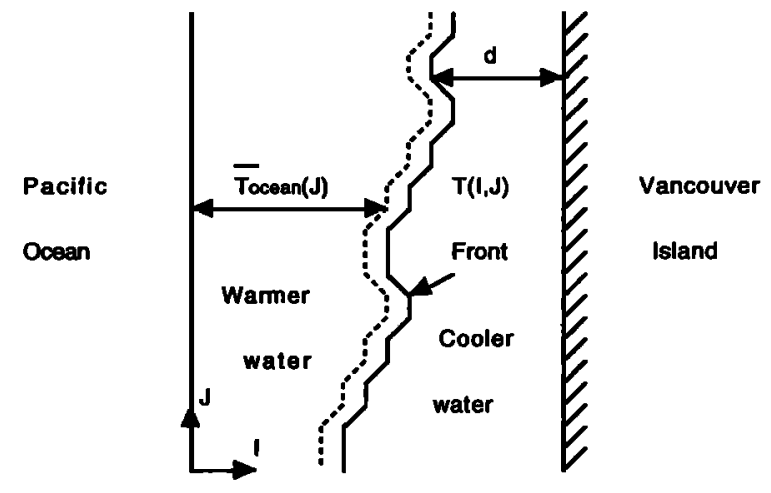

Fig. 6. Cool and warm regions used for calculating the coolness index $C$ as discussed in the text. 


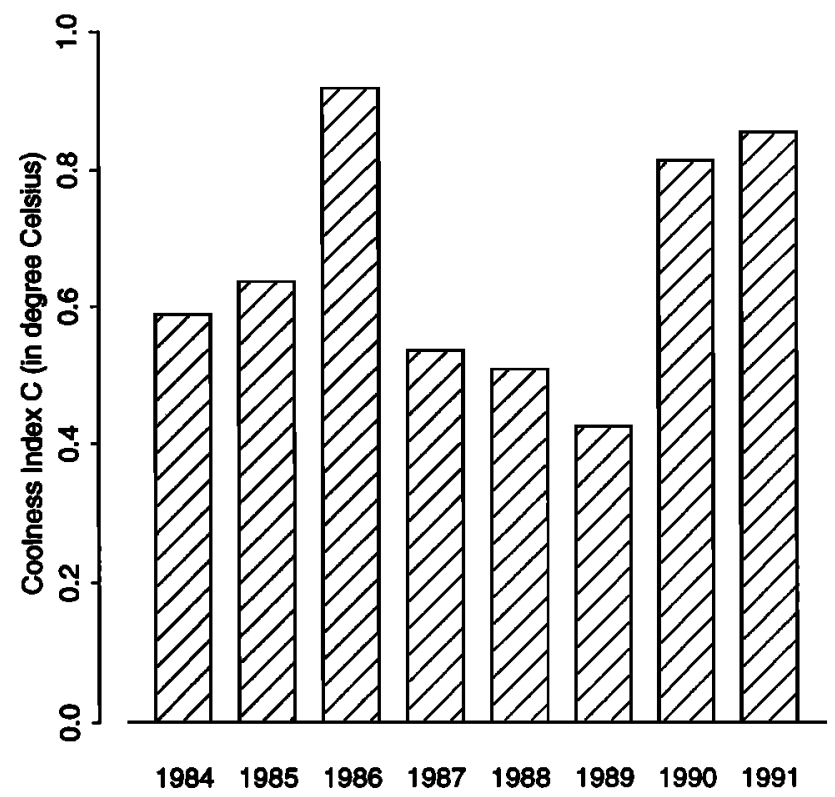

Fig. 7. Summer coolness index $C$ off Vancouver Island derived from satellite-sensed SST data (using images from June to September). The index $C$ defined by (6) indicates on average how much the SST in the coastal region is cooler relative to the offshore SST.

spring, summer, autumn and winter means of the monthly SOI as defined by Chelliah [1990]). The highest correlation of -0.92 was attained when the summer $C$ was correlated with the SOI from the following spring, which means that cool summer coastal SST (high $C$ index) off Vancouver Island preceded the El Niño warm events (low SOI), which peaked at around the following spring. From assuming one degree of freedom for each year, a correlation of -0.92 is significant at the $99 \%$ level, though for such short interannual time series, the significance level cannot be determined reliably. Clearly a much longer time series for $C$ is needed before one can confirm this relationship between the two indices.

\section{Correlations Between EOFs and Various Indices}

To examine the relationship of the dominant gradient EOF modes with various indices, we calculated the correlations between the weekly averaged time series of the first four gradient EOF temporal amplitudes with various related time series. From the daily Bakun upwelling indices (kindly provided by NOAA/NMFS Pacific Fisheries Environmental Group, Monterey, California, at two offshore sites, $\left(48^{\circ} \mathrm{N}\right.$, $125^{\circ} \mathrm{W}$ and $51^{\circ} \mathrm{N}, 131^{\circ} \mathrm{W}$ ), we computed the weekly Bakun indices by averaging the daily data over the days when satellite images were available. The Bakun coastal upwelling indices were based on calculations of offshore Ekman surface wind transport from surface atmospheric pressure data [Bakun, 1973]. Weekly time series for the coolness index $C$ and for the Fraser River discharge measured at Hope, British Columbia, were prepared in a similar way.

The correlation coefficients between the time series of the EOF modes and various indices are listed in Table 2. Correlations of the coolness index $C$ with the first four EOF

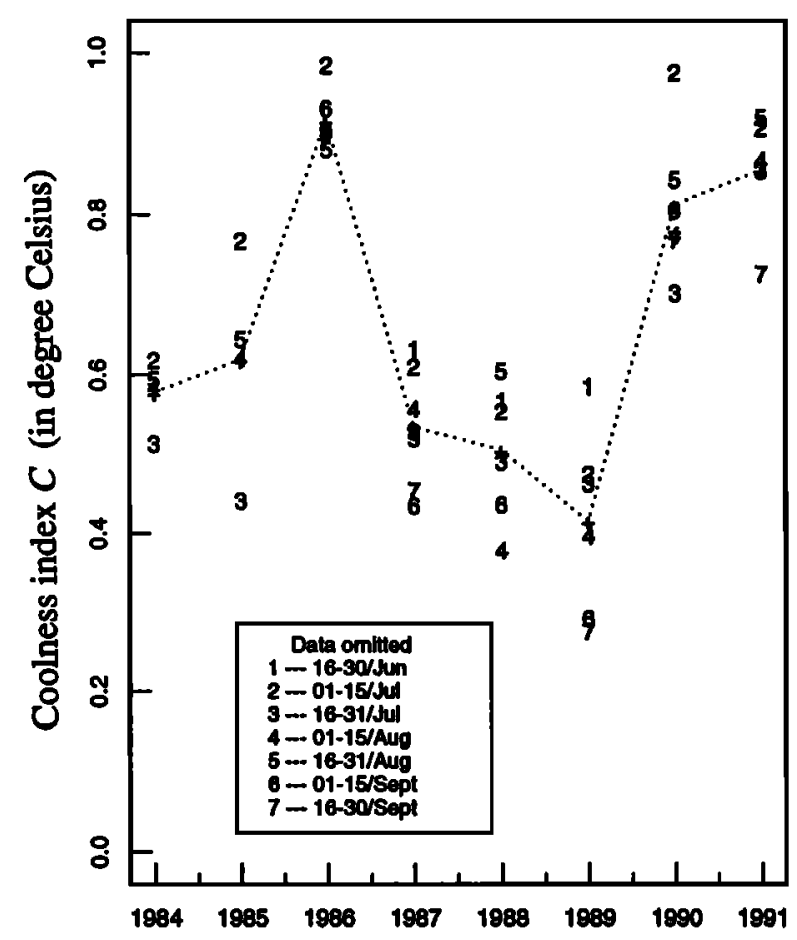

Fig. 8. Fluctuations in the summer coolness index $C$ as data from various 2-week intervals are omitted in the computation of $C$ to simulate missing data from clouds. The $C$ values computed with data omitted are marked by the symbols 1 to 7 corresponding to the seven possible 2-week intervals omitted, and the $C$ values with no missing data are marked by the + symbol (linked by the dashed curve).

temporal amplitudes showed the highest correlation of 0.70 with mode 2 , the next highest correlation of 0.59 with mode 1 , and insignificant correlations with modes 3 and 4. This suggests that the first two EOF modes strongly influenced the overall coolness index $C$.

The satellite data tend to suffer from fair-weather bias, i.e., satellite images are available only during cloud-free days with high pressure over the northeast Pacific, which correspond to days with upwelling favorable winds. Thus, despite the bias in the satellite collection, the occurrence of strong upwelling should coincide with days of high pressure and clear weather, and hence would have been included in

TABLE 2. The Cross Correlations Between Time Series of the Gradient EOF Modes and Various Indices

\begin{tabular}{cccccc}
\hline & $C$ & Mode 1 & Mode 2 & Mode 3 & Mode 4 \\
\hline$C$ & & $0.59 / 99 \%$ & $\mathbf{0 . 7 0 / 9 9 \%}$ & $0.07 / 30 \%$ & $0.01 / 6 \%$
\end{tabular}

Bakun.S -0.13/50\% $-0.10 / 48 \%-0.05 / 21 \% \quad 0.24 / 88 \%-0.10 / 54 \%$

\section{Bakun.N - $0.06 / 39 \%-0.30 / 96 \% \quad 0.20 / 80 \% \quad 0.30 / 96 \% \quad 0.34 / 98 \%$}

Discharge $-0.43 / 98 \%-0.23 / 84 \%-030 / 92 \% \quad 0.24 / 91 \%-0.26 / 91 \%$

The levels of significance given after the correlation coefficients, were calculated with the number of degrees of freedom estimated by the method of Davis [1976]. Correlations above the $90 \%$ significance level were printed in bold, and they all have at least 30 degrees of freedom. $C$ denotes the coolness index, while Bakun.S and Bakun.N represent the Bakun upwelling index at $48^{\circ} \mathrm{N}, 125^{\circ} \mathrm{W}$ and at $51^{\circ} \mathrm{N}, 131^{\circ} \mathrm{W}$, respectively. 
our data collection and incorporated into our indices. Table 2 also shows the correlation between our indices with the Bakun upwelling indices. The Bakun index at $48^{\circ} \mathrm{N}, 125^{\circ} \mathrm{W}$ (Bakun.S), lying just south of our study region, showed generally low correlations with the EOF amplitudes. The Bakun index at $51^{\circ} \mathrm{N}, 131^{\circ} \mathrm{W}$ (Bakun.N), lying just to the northwest of our domain showed higher correlations with the EOF amplitudes. Except with the first EOF amplitude, the positive correlations between Bakun. $N$ and the other EOF amplitudes meant that an upwelling favorable Bakun index tended to concur with cool coastal SST in these modes. Since modes 3 and 4 involved, respectively, plumes off Brooks Peninsula and Cape Scott, both in the northem part of our study region, it is not surprising that they were correlated with the Bakun index to the north (Bakun.N) than with Bakun.S. The highest correlation, which occurred between mode 4 and Bakun. $N$, is expected since of the four modes, mode 4 with the Cape Scott plume must have its upwelling most strongly affected by winds around the northern part of our domain. The negative correlation between the first EOF amplitude and Bakun.N seemed to suggest that an upwelling favorable Bakun index tended to concur with the weakening of the mode 1 coastal upwelling pattern, in contradiction to our expectations. To explain this paradox, we note that the mode 1 amplitude time series (Figure 5) has a notable seasonal trend, indicating an intensification of the pattern of Figure $3 a$ from June to September. The corresponding seasonal trend for the Bakun. $\mathbf{N}$ index showed a decrease from June to September (not shown). Hence the negative correlation between the two could simply be due to opposite seasonal trends.

While the coolness index $C$ was not correlated with either Bakun.N or Bakun.S, $C$ and the Fraser River discharge had a significant negative correlation of -0.43 (Table 2). In summer, Fraser River water and thus surface water in the Strait of Georgia are normally warmer than that in the Strait of Juan de Fuca, where there is much tidal mixing. Hickey et al. [1991] reviewed the transport process of the monthly pulse of warm, fresh water exiting the Strait of Georgia from satellite SST images. They pointed out that the outflow of this anomalously warm fresh water was one of the causes for warmer water appearing at the mouth of the Juan de Fuca Strait. A large outflow event from Fraser River implies that more warm water flows through the Strait of Juan de Fuca, which diminishes the overall coolness index of our study region, hence the observed negative correlation between discharge and $C$. Discharge was also negatively correlated with the EOF amplitudes in Table 2 except with mode 3, where the marginally significant positive correlation suggests that strong discharges tended to concur with the appearance of the cold squirt off Brooks Peninsula.

\section{Summary and Discussion}

EOF analysis of the spatial variances for 133 nearly cloud-free SST images provided us the first systematic classification of the summer SST patterns off Vancouver Island, and to follow their evolution as summer progresses. The first EOF mode of spatial variance resembled the mean SST pattern obtained from averaging all images, while the second mode revealed upwelling controlled by the bottom topography. The third mode corresponded to cool water extending southwestward off Brooks Peninsula, while the fourth mode showed a cool water plume extending off Cape Scott at the northern tip of Vancouver Island. These 4 modes accounted for respectively, 33, 12, 10 and $5 \%$ of the SST variance. As $60 \%$ of the total variance can be accounted for with only four modes, we conclude that the EOF method is highly effective in condensing the huge amount of satellite SST data off Vancouver Island.

Correlations between Bakun upwelling indices and our EOF temporal amplitudes showed that SST in our study region was significantly influenced by the Bakun index to the northwest of our domain but insignificantly by the Bakun index immediately to the south of our domain. That the wind (as represented by the Bakun index) to the north had a greater influence than the wind to the south of our region could be explained by the fact that modes 3 and 4 had plumes extending southwestward from Brooks Peninsula and Cape Scott, both in the northern part of our domain. These SST EOF time series can potentially be used as new upwelling indices, providing a measure of the fine features of coastal upwelling, which the Bakun index, based on large-scale geostrophic wind, cannot.

From these images, we also constructed an overall coolness index $C$, measuring the coolness of the coastal upwelling region relative to the offshore region. The negative correlation between $C$ and the Fraser River discharge tends to suggest that high discharge concurs with warmer SST in our study region. Interannual variability in the average value of $C$ over each upwelling season revealed the summers of 1986 and 1991 to have the coolest coastal water. These two cool anomalies slightly preceded the last two ENSO events (1986-1987 and 1991-1992).

Acknowledgments. We are indebted to Denis Laplante and Gordon Staples for the satellite images, and to W. J. Emery for starting the satellite collection. D. Bancroft and W. R. Crawford kindly drew our attention to the fair-weather bias in the data. This research was supported by the Canadian Natural Sciences and Engineering Research Council and the Department of Fisheries and Oceans.

\section{REFERENCES}

Bakun, A., Daily and weekly upwelling indices, west coast of North America, 1946-71, NOAA Tech. Rep., NMFS-SSRF-671, U.S. Dep. of Commer., Washington, D. C., 1973.

Burgert, R., and W. W. Hsieh, Spectral analysis of the AVHRR sea surface temperature variability off the west coast of Vancouver Island, Atmos.-Ocean, 27, 577-587, 1989.

Chelliah, M., The global climate for June-August, 1989: A season of near normal conditions in the tropical Pacific. J. Clim., 3, 138-162, 1990.

Davis, R. E., Predictability of sea surface temperature and sea level pressure anomalies over the north Pacific Ocean. J. Phys. Oceanogr., 6, 249-266, 1976.

Denman, K. L., and H. J. Freeland, Correlation scales, objective mapping, and statistical test of geostrophy over the continental shelf, J. Mar. Res., 43, 517-539, 1985.

Emery, W. J., and L. A. Mysak, Dynamical interpretation of satellite-sensed thermal features off Vancouver Island, J. Phys. Oceanogr., 10, 961-970, 1980.

Emery, W. J., A. C. Thomas, M. J. Collins, W. R. Crawford, and D. L. Mackas, An objective method for computing advective surface velocities from sequential Infrared satellite images, $J$. Geophys. Res., 91(C11), 12,865-12,878, 1986.

Freeland, H. J., and K. L. Denman, A topographically controlled 
upwelling center off southern Vancouver Island. J. Mar. Res., 40, 1068-1093, 1982.

Hickey, B. M., R. E. Thomson, H. Yih, and P. H. LeBlond, Velocity and temperature fluctuations in a buoyancy-driven current off Vancouver Island, J. Geophys. Res., 96(C6), 10,50710,538, 1991.

Ikeda, M., and W. J. Emery, A continental shelf upwelling event off Vancouver Island as revealed by satellite infrared imagery, J. Mar. Res., 42, 303-317, 1984.

Ikeda, M., L. A. Mysak, and W. J. Emery, Observation and modeling of satellite-sensed meaders and eddies off $V$ ancouver Island, J. Phys. Oceanogr., 14, 3-21, 1984.

Kelly, K. A., The influence of winds and topography on the sea surface temperature patterns over the northem California slope, J. Geophys. Res., 90(C6), 11,783-11,798, 1985.

Kelly, K. A., Comment on "Empirical orthogonal function analysis of advanced very high resolution radiometer surface temperature patterns in Santa Barbara Channel" by G. S. E. Lagerloef and R. L. Bernstein, J. Geophys. Res., 93(C12), 15,753-15,754, 1988.

Lagerloef, G. S. E., and R. L. Bernstein, Empirical orthogonal function analysis of advanced very high resolution radiometer surface sea temperature patterns in Samta Barbara Channel, J. Geophys. Res., 93(C6), 6863-6873, 1988.

Lauritson, L., G. Nelson, and R. W. Porto, Data extraction and calibration of TIROS-N/NOAA A-G radiometers, NOAA Tech. Memo., NESS 107, 44-46, 1979.

Overland, J. E., and R. W. Preisendorfer, A significance test for principal components applied to a cyclone climatology, Mon. Weather Revi., 110, 1-4, 1982.

Paden, C. A., M. R. Abbott, and C. D. Winant, Tidal and atmospheric forcing of the upper ocean in the Gulf of California,
Part I, Sea surface temperature variability, J. Geophys. Res., 96(C10), 18,337-18,359, 1991.

Preisendorfer, R. W., Principal component analysis in meteorology and oceanography, Elsevier, New York, 425 pp., 1988.

Thomson, R. E., and J. F. R. Gower, A wind-induced mesoscale eddy over the Vancouver Island continental slope, J. Geophys. Res., 90(C5), 8981-8993, 1985.

Thomson, R. E., B. M. Hickey, and P. H. LeBlond, The Vancouver Island coastal current: fisheries barrier and conduit. Effects of Ocean Variability on Recruitment and an Evaluation of Parameters Used in Stock Assessment Models, edited by R. J. Beamish and G.A. McFarlane, Can. Spec. Publ. Fish. Aquat. Sci., 108, 265-296, 1989.

Wang, D. C. C., A.H. Vagnucci, and C. C. Li, Digital image enhancement: A survey, Comput. Vision Graphics Image Processing, 24, 363-381, 1983.

Weaver, A. J., and W. W. Hsieh, The influence of buoyancy flux from estuaries on continental shelf circulation, $J$. Phys. Oceanogr., 17, 2127-2140, 1987.

W. Fang and W. W. Hsieh, Department of Oceanography, University of British Columbia, Vancouver, B. C., Canada V6T $1 \mathrm{ZA}$.

(Received July 29, 1992;

revised April 8, 1993;

accepted May 4, 1993.) 